\title{
Inspired by structured decision making: a collaborative approach to the governance of multiple forest values
}

\author{
Johanna Johansson ${ }^{1}$, Camilla Sandström ${ }^{2}$ and Tomas Lundmark ${ }^{3}$
}

\begin{abstract}
Since the 2000s, consensus-oriented decision making has become increasingly common in the management of natural resources because of the recognition that collaborative processes may enhance the legitimacy of decision making and facilitate effective implementation. Previous research has identified a number of problems with the design and practical facilitation of collaborative processes. Structured decision making (SDM) has been developed as an alternative suitable for decision making characterized by complexity, stakeholder controversy, and scientific uncertainty. Our aim was to investigate the feasibility and practical relevance of collaboration and dialogue inspired by SDM in the sphere of forest management. The methods used included analyses of meetings records and semistructured interviews with participating stakeholders and organizers of a collaborative process focused on improving the management of Swedish forests in the young forest phase. The results show that the SDM rationale of step-by-step teamwork, the involvement of experts, and guidance by an independent facilitator has a number of merits. These merits included the creation of genuine discussion with careful consideration of different interests and values, thus building trust among stakeholders and the Swedish Forest Agency. However, at the end of the process, some issues still remained unclear, including how the decision options would be made practically useful and accessible to forest owners. Furthermore, concerns were raised about the lack of novelty of the options. As a result, there was uncertainty about the extent to which the options would contribute to a more varied forest landscape given the multiple values involved. We conclude with some remarks on the potential future of engaging SDM in the forestry sector.
\end{abstract}

Key Words: adaptive management; collaboration; forest management; structured decision making

\section{INTRODUCTION}

Consensus-oriented decision making has become increasingly common in the management of natural resources. Public agencies set up collaborative processes to facilitate outcomes that could not be accomplished by the state on its own without the engagement of private actors (Ansell and Gash 2007, Mårald et al. 2015, Bodin 2017). Such processes with broad stakeholder involvement are often set up to enhance the support (i.e., legitimacy to the public) of decision making and so generate effective implementation on the ground (Reed 2008, Johansson 2016). However, although collaborative processes have become important in managing disputes over resources, the outcomes remain largely unexplored (Ansell and Gash 2007, Lockwood et al. 2010, Emerson and Nabatchi 2015). Furthermore, the role of scientific knowledge and expertise in decision making is often contested. For instance, it is not known to what extent deliberations and policies take into account scientific knowledge about how trade-offs between multiple values can be handled or how stakeholders deal with the fact that such research is associated with major uncertainties (Uggla et al. 2016).

Hence, several challenges persist in the design and practical facilitation of collaborative processes. As a way to deal practically with such challenges, a model of structured decision making (SDM) has been developed (Gregory et al. 2012). Briefly, an SDM process recognizes that management choices are often characterized by a high degree of stakeholder controversy, with the result that consensus is seldom possible or even desirable (Gregory et al. 2001). Rather, it is important that collaborative processes address the different values held by stakeholders, that alternative options and their consequences are developed, and that trade-offs between competing objectives are considered. A central starting point is that management options are surrounded by a high degree of scientific uncertainty. It is also important, however, to investigate when the value base determines a position. Reduced uncertainty does not mean that decision support is improved (Mårald et al. 2015). Public agencies often have little knowledge about how to deal with uncertainty and value-based controversy in resource management (Gregory et al. 2012).

The potential incentives and obstacles to adopting an SDM approach are especially intriguing when it comes to the governance of forests because of the long-term perspectives attending forest issues (Ogden and Innes 2009, Marcot et al. 2012, Ferguson et al. 2015). Given the predicted climate change scenarios, stakeholder processes and strategies targeting the role of forests in mitigating and adapting to climate change are becoming increasingly important (Ogden and Innes 2009, Wellstead et al. 2013, Rist et al. 2016). Forests are a resource with high public value, even when privately owned, but it is difficult to determine who has the responsibility for harmonizing multiple values (environmental, social, and economic) in the management of forests. In Sweden, for instance, the majority of forest land is owned by small-scale private forest owners or large-scale forest companies. By law, all categories of forest owners have significant room to maneuver in finding ways to harmonize biomass production, conservation values, and forests' social and aesthetic values (Beland Lindahl et al. 2017). Partly as a result of the diverse ownership structure of the land and international pressures for biodiversity conservation, collaborative processes have become common in the governance of Swedish forests since the early 2000s. The deregulation associated with the Swedish Forestry Act

${ }^{1}$ School of Natural Sciences, Technology and Environmental Studies, Södertörn University, ${ }^{2}$ Department of Political Science, Umeå University,

${ }^{3}$ Department of Forest Ecology and Management, SLU (Swedish University of Agricultural Sciences) 
in the 1990s, and persistent disagreement between stakeholders about the activities of intensive forest management, have created an ongoing need for forest owners and other stakeholders to meet and deliberate about the challenges of combining forest management with biodiversity conservation and other forest uses (Mårald et al. 2015, Beland Lindahl et al. 2017). Despite the fact that collaboration and dialogue have been an integral part of Swedish forest policy since the 2000s, there is a clear lack of studies analyzing their feasibility and outcomes (see Sundström 2010, Johansson 2013, Mårald et al. 2015, Johansson 2016). It is thus important to evaluate the incentives for and obstacles to more structured ways of facilitating collaborative processes in forest management in a Nordic context.

Our aim is to analyze the feasibility and practical relevance of collaboration and dialogue inspired by SDM in the governance of multiple forest values. We did this by looking at the Swedish Forest Agency's commission on adaptive forest management (Swedish Forest Agency 2013, 2016a). The work of this commission provides an opportunity to explore how public agencies deal with complex issues characterized by uncertainty and stakeholder controversy. In particular, we examine a stakeholder dialogue that took place during the final year of the commission and focus on the management of Swedish forests in the young forest phase. We begin by outlining an analytical framework on collaborative processes and SDM theory and logic, including a review of previous research. The methods follow, including brief background information about Swedish forest use and policy and the particular case studied. We then analyze the Forest Agency's collaborative process and how it was inspired by SDM in two parts: we analyze how SDM has been interpreted and applied in practice, and then we offer a summary of stakeholders' perceptions of the objectives, procedures, and outcomes of the SDM process. Finally, we review the feasibility and practical relevance of collaboration in Swedish forestry and the potential for engaging SDM in the forest sector.

\section{DESIGNING COLLABORATION USING A STRUCTURED DECISION PROCESS}

Since the 2000s, the role of the state in public administration has changed toward more inclusion of nonstate actors in policy making and implementation (Denhardt and Denhardt 2011, Bodin 2017). This deliberative turn, or the move from government to governance, may signal the impossibility of handling complex problems such as climate change without cooperation with nonstate actors. The inclusion of various interest groups in the decision-making process is frequently credited with generating more legitimate decision-making processes and effective achievement of public goals (Howlett and Rayner 2006, Hysing 2009). According to Denhardt and Denhardt (2011), this form of governance requires a public administration that helps citizens articulate their shared interests and have them met through public institutions characterized by responsiveness. Such institutions must trust in the efficacy of collaboration and work to bring proper stakeholders to the table to seek solutions to the problems that communities face. The role of government is to facilitate solutions to public problems and be responsible for assuring that the decision-making process is consistent with the public interest and democratic norms of justice and fairness. The role of public administration is to take an active role in setting up arenas in which various stakeholders can meet and articulate shared values and collective responsibility for the public interest (Denhardt and Denhardt 2011).

There are several challenges in the design and practical facilitation of collaborative processes. To begin with, any form of collaboration requires the true commitment of various stakeholders. Stakeholders need to be motivated to participate and able to participate on equal terms, they need to commit to the decisions made, and at the end, they need to feel that the time spent was worth the effort (Kangas et al. 2010). This outcome requires broad stakeholder participation, transparent decisions, awareness of collective responsibility, trust building, and measurable outcomes (Johansson 2016). At the same time, public agencies may struggle with the different expectations of each of the participants and their own desires (Wesserlink et al. 2011, Mårald et al. 2015, Westberg and Waldenström 2017). A recent study of Finnish forest governance highlights the importance of past decision-making processes involving the stakeholders, the extent to which all relevant stakeholders participate in the deliberations, and the extent to which divergent views are considered in a balanced and transparent manner (Sarkki and Heikkinen 2015; see also Ansell and Gash 2007). An analysis rooted in such an approach considers to what extent an initiative encourages the emergence of shared understandings or new solutions and respectful consideration of all opinions.

SDM was developed as a practical way to deal with the above challenges (Gregory et al. 2001, 2012). The SDM approach has emerged from the need to provide more informed decisions about environmental policy choices and their associated ecological uncertainties. It aims to provide better solutions, more productive participation by stakeholders, and greater acceptance of resource management. It has been defined as "the collaborative and facilitated application of multiple objective decision making and group deliberation methods to environmental management and public policy" (Gregory et al. 2012:6). The primary purpose of SDM is to aid and inform decision makers rather than to prescribe a preferred solution. In practice, it is a prescriptive approach that draws on decision analysis and applied ecology along with insights gained from other behavioral sciences, group dynamics, and negotiation theory. It is an explicit step-by-step process that a group agrees to follow. It takes into consideration both values (what is important) and consequences (what is likely to happen if an alternative is implemented). An SDM approach recognizes that different values denote what matters, that is, what is important in the context of the specific problem at hand. The goal of the SDM process is essentially to clarify possible actions and their implications across a range of relevant concerns by (1) clarifying the decision context and (2) setting objectives. Thus, it focuses on (3) identifying, comparing, and iteratively refining alternatives. These alternatives should reflect substantially different approaches to a problem, based on different priorities, and should present decision makers with real choices. Choosing a preferred alternative will involve an open dialogue about tradeoffs.

The stakeholders involved in an SDM process need to be prepared to learn, to explore competing hypotheses, and to build a common understanding of what constitutes the best available information for (4) estimating consequences and (5) evaluating trade-offs. In 
Table 1. Themes and questions or approaches involved in structured decision making (SDM). Source: adapted from Gregory et al. (2012).

\begin{tabular}{|c|c|}
\hline Theme & Questions and approaches \\
\hline $\begin{array}{l}\text { Clarifying the } \\
\text { decision context }\end{array}$ & $\begin{array}{l}\text { What is the decision to be made, by whom, and when? } \\
\text { What is the range of alternatives and objectives that can be considered (what is in and what is out)? } \\
\text { What kind of decision is needed, and how could it be structured usefully? } \\
\text { What kind of analytical tools are needed? } \\
\text { What level and kind of consultation is needed? } \\
\text { What is required to make an informed choice? } \\
\text { Lay out a road map so all parties understand what will happen and when }\end{array}$ \\
\hline $\begin{array}{l}\text { Setting objectives } \\
\text { and developing } \\
\text { alternatives }\end{array}$ & $\begin{array}{l}\text { What objectives and performance measures will be used to identify and evaluate the alternatives? } \\
\text { What matters about the decision? } \\
\text { Create performance measures for assessing and reporting how well an alternative performs with respect to an objective } \\
\text { Objectives and measures must be carefully defined and accepted by key stakeholders as the basis for evaluating management } \\
\text { alternatives; the goal for stakeholders is to agree on what things matter } \\
\text { Develop creative alternatives that are responsive to the defined objectives; alternatives should reflect substantially different } \\
\text { approaches to a problem based on different priorities across objectives and should present decision makers with real choices }\end{array}$ \\
\hline $\begin{array}{l}\text { Estimating } \\
\text { consequences }\end{array}$ & $\begin{array}{l}\text { Consequences of the alternatives on the performance measures are estimated and presented in a consequence table; this is a } \\
\text { technical task, undertaken by experts. } \\
\text { Groups involved in SDM will need to be prepared to learn, to explore competing hypotheses, and to build a common understanding } \\
\text { of what constitutes the best available information for assessing consequences } \\
\text { Provide an accurate representation of uncertainty; attempts to reduce uncertainty should be made consistent with the project goals, } \\
\text { timeline, and resources }\end{array}$ \\
\hline Evaluating trade-offs & $\begin{array}{l}\text { Choose an alternative or set of alternatives that achieves an acceptable balance across multiple objectives } \\
\text { Expose and facilitate an open dialogue about the trade-offs } \\
\text { Stakeholders should state their different alternatives based on credible technical information about the estimated consequences }\end{array}$ \\
\hline $\begin{array}{l}\text { Implementation and } \\
\text { way forward }\end{array}$ & $\begin{array}{l}\text { SDM should promote learning and build management capacity to make better decisions in the future } \\
\text { Participants should be prepared to learn over time and make a formal commitment to review decisions when new information is } \\
\text { available } \\
\text { This step includes monitoring programs that are linked to objectives, and performance measures that are used to evaluate } \\
\text { management alternatives; this emphasizes the central role of learning throughout the process }\end{array}$ \\
\hline
\end{tabular}

so doing, they will clarify areas of agreement and disagreement and the reasons for these disagreements. The results of an SDM process are useful to decision makers whether or not a consensus is reached. Public programs often stress the importance of consensus among stakeholders; it is seen as a goal to be striven for, even though it may not always be attainable. However, dispute resolution and consensus building should be avoided in an SDM approach (Gregory et al. 2001). Rather, SDM is concerned with (6) developing learning and building management capacity so as to make better decisions in the future. Instead of seeking to resolve disputes, the deliberative process should focus on aiding decisions, both by the stakeholders and by the agency empowered to make the final decision. This requires an open process with thoughtful exploration of the values of different stakeholders. Conflict among group members should not be viewed as a problem to be overcome but as an opportunity to clarify values and facts relevant to the decision at hand. There is an emphasis on learning over time, including a formal commitment to review decisions when new information becomes available. What exactly is done at each step of an SDM process and the level of rigor and complexity will depend on the nature of the decision, the stakes, the resources, and the timeline (see Table 1 for a guide to the step-by-step approach).

Our review of the literature shows that SDM has been interpreted and applied in various ways in resource management in the past few years. Recent research has analyzed its use in settings such as supplementary feeding in species conservation (Ewen et al. 2015), recreational fisheries (Irwin et al. 2011), the selection of monitoring variables and management priorities for salt marsh ecosystems (Neckles et al. 2015), and the restoration of river basins (Kozak and Piazza 2015). These studies have drawn attention to specific, well-defined problems in marine conservation. However, few studies have looked at the complexity of governing resources with multiple uses. As regards forestry, we have identified studies that address parcelization and forest fragmentation of private lands (Ferguson et al. 2015), the implementation of regional forest management plans (Ogden and Innes 2009), and the management of national forests (Marcot et al. 2012). The approach of Ferguson et al. (2015) is of particular interest: The purpose of their study was to help landowners identify which decision options would be most likely to result in outcomes that meet objectives related to forest sustainability. The study first identified landowners' multiple objectives and their relative importance, and then modeled the probability of the different outcomes for each decision option. The authors concluded that SDM may well help land owners to identify creative decision options that are most likely to meet their objectives. Furthermore, they confirm that SDM is an effective approach with which to evaluate options rigorously for decision problems that are controversial. From a different viewpoint, Marcot et al. (2012) provide an SDM approach to the study of three case studies concerning national forest land management plans and project plans. They came to the conclusion that SDM can be helpful in decomposing and understanding complex problems, yet the key challenge is how to bring these tools and processes into daily implementation. Ogden and Innes (2009) identified 30 forest practitioners who were involved in the implementation of a regional forest management plan in identifying climate change vulnerabilities and evaluating adaptation options. The practitioners identified several decision options, which provided insight into the readiness of practitioners 
to engage in adaptive strategies in a regional context. Here, we build on these review examples and provide a case-based assessment of an SDM-inspired approach in the Swedish forest sector.

\section{CASE STUDY AND METHODS}

Sweden is one of the most extensively forested countries in Europe, with 28 million ha of forest land, of which approximately $75 \%$ is under active management. Sweden holds just under $1 \%$ of the world's commercial forest area, but provides $10 \%$ of the sawn timber, pulp, and paper that is traded on the global market. The forest industry accounts for between 9 and $12 \%$ of Swedish industry's total employment, exports, sales, and added value. Close to $90 \%$ of paper and pulp production is exported, and the corresponding figure for sawn-wood products is almost $75 \%$. These figures make Sweden the world's third largest exporter of pulp, paper, and sawn timber (Royal Swedish Academy of Agriculture and Forestry 2015). Sweden has a relatively high percentage of privately owned forests: approximately $50 \%$ of the country's forest lands are owned by nonindustrial private forest owners; private corporations own 25\%; the state (including stateowned corporations) owns $17 \%$; and other private and public bodies own the remaining 8\% (Swedish Forest Agency 2013).

To strengthen environmental considerations in forest management, the Forestry Act of 1993 (which is still in force) gave equal priority to biodiversity conservation and timber production. However, the Act sets only minimum criteria related to both goals and does not stipulate how they are to be achieved. Instead, Swedish forest policy explicitly affirms the importance of "freedom with responsibility," granting all Swedish forest owners, public and private, large-scale and small-scale, substantial scope to decide how to incorporate environmental protection in the management of their forests (Johansson and Keskitalo 2014, Beland Lindahl et al. 2017). Previous research has shown that forest owners have multiple objectives, suggesting that an emphasis on only economic benefits is not desirable from the forest owners' point of view (Bjärstig and Sténs 2018). However, a recent study of Swedish forest policy has found that the current governance model adapts a "more-of-everything" pathway, in which various ecological, economic, and social goals are expected to be prioritized and achieved simultaneously (Beland Lindahl et al. 2017). However, the current forest policy provides little indication of exactly how, and to what extent, the different objectives should be achieved. The analysis by Beland Lindahl et al. (2017) further shows that Swedish forest policy has traditionally prioritized the economic dimension of sustainability, and increasing production continues to be prioritized because of climate change mitigation and economic development. As a result of the deregulation of the Swedish forest sector in the 1990s, the use of command-and-control regulations has decreased, and the use of information and knowledge campaigns, advice, and different forms of collaborative processes has increased (Beland Lindahl et al. 2017). Various forms of collaborative processes have been organized by the Swedish Forest Agency on numerous occasions (e.g., Schlyter and Stjernquist 2010, Sundström 2010, Mårald et al. 2015, Johansson 2016). For decades, controversies over forestry and environmental issues have been common. The lack of regulatory clarity and scientific uncertainty about sustainable harvest levels and biodiversity protection may also allow stakeholders with dissimilar interests to justify their standpoints (Uggla et al. 2016). As a result, there is a need to find ways to develop models and processes in which scientific uncertainty and stakeholders' divergent views can be handled (Johansson 2016, Uggla et al. 2016).

It is in this context that adaptive management has come to the fore. This approach to the management of complex systems is based on learning, thus offering a social steering instrument that complements command-and-control regulations (Rist et al. 2016). This approach fits well with the growing demand for alternatives to Sweden's current dominant silvicultural system, driven by a desire to increase biomass production, meet environmental targets, and mitigate climate change. However, diversified forest management that deviates from well-established practices carries many uncertainties that are especially evident in cases with diverse land ownership and long rotation periods (Rist et al. 2016). In 2013, the Swedish government commissioned the Swedish Forest Agency, together with the Swedish University of Agricultural Sciences (SLU), to develop a model of adaptive forest management (Swedish Forest Agency 2013, 2016a). The overall aim was to create conditions for higher biomass production and better environmental status for Swedish forests. The Agency's interpretation of adaptive management focused on developing knowledge about sustainable forest management at the interface between science and practice. The government provided special funds for a three-year program in which a working model could be tested. In May 2013, the Agency and SLU presented a first report that proposed a working model (Swedish Forest Agency 2013). In April 2016, a final report was ready, with the results of the project (Swedish Forest Agency $2016 a$ ). One of the proposals in the first report was to establish a special stakeholder panel. The main task of this group would be to identify troublesome gaps or uncertainties related to forest management that would be appropriate to test with the adaptive model through a stakeholder dialogue process. This stakeholder group would also serve as a reference group in the implementation phase of the project. The panel was formally established in the autumn of 2013 after a request to stakeholders in the Forest Agency's National Sectoral Council. After an initial phase of process development, the panel agreed on various forest management issues that were suitable for a collaborative dialogue process. The first question to be addressed, and thus the point where the whole approach could be tested, was the management of forests in their young phase (Swedish Forest Agency 2016a,b).

This first application of the adaptive model provides a case study of feasibility and the practical relevance of collaboration and dialogue in governance when there are multiple forest values (Fig. 1). This case study takes a qualitative approach and includes 14 semistructured interviews. The interviewees comprised all of the stakeholders who participated in the collaborative process in 2015-2016, two officials from the Swedish Forest Agency who were responsible for organizing the process, and one independent facilitator who facilitated all the meetings. The stakeholders represented a number of diverse interests: hunting (2 stakeholders), reindeer husbandry (1), environmental values (1), energy (1), forestry services (1), large-scale forestry (2), small-scale forestry (1), tourism (1), and outdoor activity (1). The interviews were conducted during the spring of 2016, either face-to-face or by telephone, and lasted from $40 \mathrm{~min}$ to $2 \mathrm{~h}$. All respondents were assured of anonymity. The interviews were recorded and 
Fig. 1. Conceptual model of adaptive forest management.

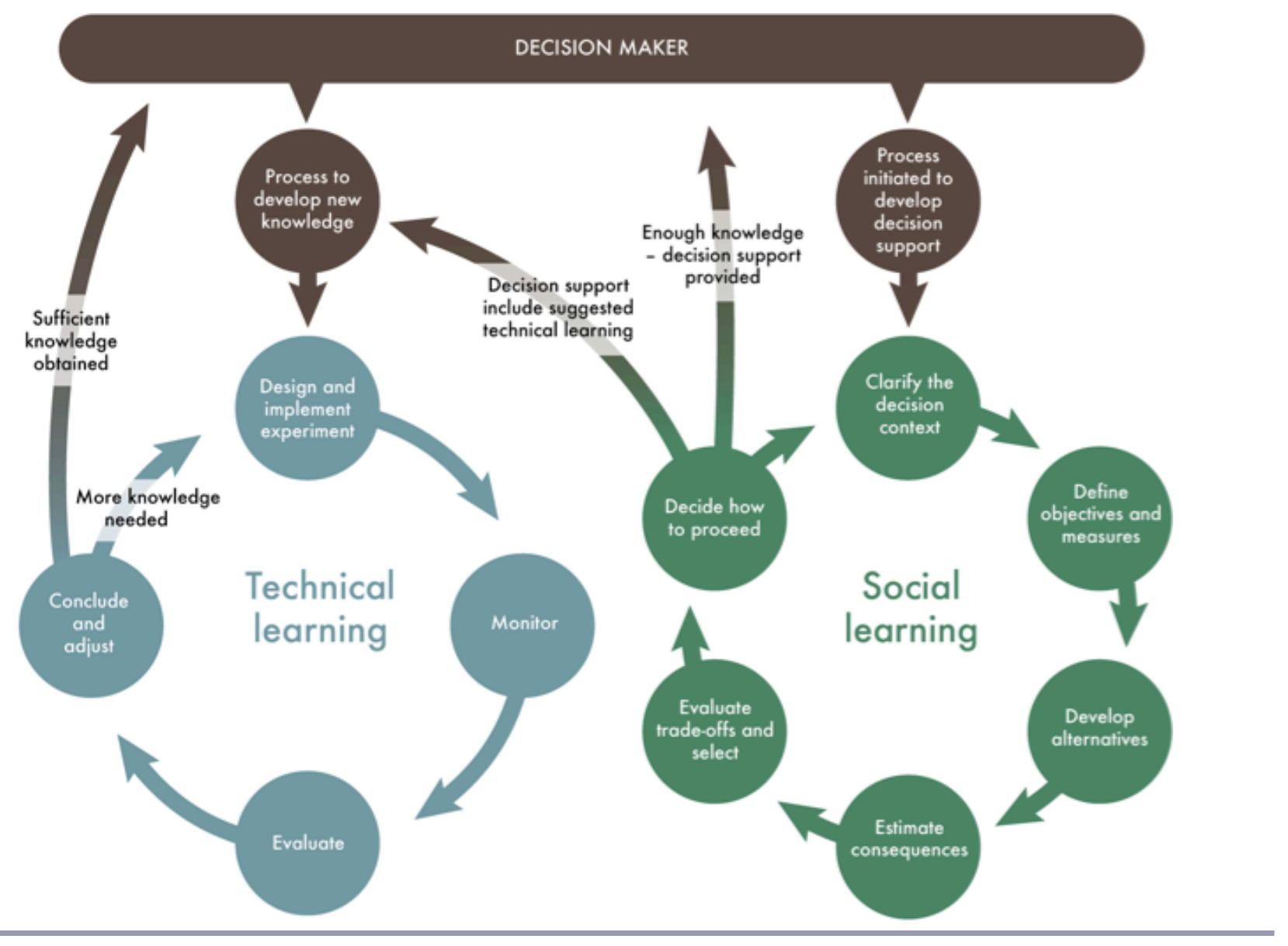

transcribed verbatim. The quotations included here were translated from Swedish into English. Because the interviews were semistructured, they were generally open, allowing the researcher and respondent to examine new ideas that were brought up during the interview. A number of questions were thought about well in advance, including an interview guide with topics and questions drawing on collaborative governance and SDM reasoning (Table 2). References to interview participants are in the form "IP $x$," where $x$ is the number of the person interviewed.

Our results also rely on the analysis of records from the seven dialogue meetings that were held and previous research on collaborative processes and SDM approaches. The results were categorized into two sections. First, we analyze how SDM has been interpreted and applied in practice (with particular focus on the adaptive model in Fig. 1). Second, we offer a summary of stakeholders' perceptions of the objectives, procedures, and outcomes of the SDM process.

\section{INSPIRED BY STRUCTURED DECISION MAKING: COLLABORATIVE PROCESS ON EVEN-AGED STAND MANAGEMENT IN THE YOUNG FOREST PHASE}

Clarifying the decision context and setting objectives Before the collaborative process began, the Forest Agency appointed a secretariat consisting of a facilitator, or process manager, and two administrators. The Agency proposed to follow the original step-by-step SDM approach outlined by Gregory et al. (2012) and the model of adaptive forest management developed by SLU (Fig. 1; Swedish Forest Agency 2016a). However, at the start of the exercise, it was decided to make some changes primarily related to the context of decision making. Instead of acting as the decision maker and clarifying what general objective should be met, the Agency decided to formulate the task of the process in an open-ended fashion (IP 1, 4). This also meant that the process came to focus more on developing decision support for future opportunities than on making an actual decision in the near future.

A working group with a broad representation of stakeholders was set up. Several organizations chose to participate, but some stakeholders were unable to participate, which meant that the Agency had to contact a number of other stakeholders before the working group could be considered inclusive. Particular importance was attached to ensuring that the participants held different values (Swedish Forest Agency 2016b; IP 1, 4). One important aspect of the process was engaging an independent facilitator to moderate the discussions and provide information and feedback regularly after the meetings. Right from the start, the facilitator was given quite free rein on how to interpret and proceed with the SDM approach (IP 1, 4). 
Table 2. Interview themes and questions.

\begin{tabular}{|c|c|}
\hline Interview theme & Questions asked \\
\hline $\begin{array}{l}\text { Clarifying the decision context; } \\
\text { defining objectives }\end{array}$ & $\begin{array}{l}\text { Specify whom you represent and from what perspective } \\
\text { Was the role and mandate of the commission clear from the outset? } \\
\text { Is there a specific problem that needs to be solved? } \\
\text { Has the mandate of the dialogue process changed over time? } \\
\text { Who is the end user of the forthcoming alternative(s)? } \\
\text { Who makes the final decision? } \\
\text { What goals do you consider that the dialogue process should prioritize? } \\
\text { What is important from your perspective? }\end{array}$ \\
\hline $\begin{array}{l}\text { Measuring objectives; developing } \\
\text { alternatives; estimating consequences; } \\
\text { evaluating trade-offs }\end{array}$ & $\begin{array}{l}\text { Have alternatives for young even-aged stand management been discussed and communicated in a transparent } \\
\text { manner? State your general impression of these alternatives } \\
\text { Does your option correspond to the management option proposed by the Forest Agency's experts? } \\
\text { Specify your views on the analyses done by the Forestry Research Institute; if possible, specify alternatives for } \\
\text { making trade-offs } \\
\text { Has relevant scientific research been considered? } \\
\text { Describe the role of SDM and a brief overview of what it implies in practice } \\
\text { Are these dialogue processes different from other processes in which you have taken part as a stakeholder? If so, in } \\
\text { what ways? } \\
\text { Were you able to freely express your opinions to the whole group? } \\
\text { Do you feel that your concerns were taken seriously? } \\
\text { How do you perceive access to information and the quality of meeting records? } \\
\text { What is your general impression of the role of the facilitator and the secretariat? } \\
\text { What is your view on the stakeholders that have been chosen to participate? Is anyone missing? } \\
\text { Has anyone of the stakeholders dominated the discussions or the end results? }\end{array}$ \\
\hline $\begin{array}{l}\text { Learning; implementation and way } \\
\text { forward }\end{array}$ & $\begin{array}{l}\text { What is the way forward? } \\
\text { How should the Forest Agency proceed? } \\
\text { What are the prospects for alternative management practices in young forest management? } \\
\text { Is there a need for new regulatory changes, financial aid, or other governance tools? } \\
\text { Specify incentives of and obstacles to the SDM approach and potential ways forward } \\
\text { Under what circumstances might an SDM approach be useful in the Swedish forest sector? }\end{array}$ \\
\hline
\end{tabular}

According to the Forest Agency, the main objective of the collaborative process was to develop variants of silvicultural programs (Table 3 ) for even-age forest management that could help landowners meet different land-use objectives. Groups of participants brainstormed different land-use objectives and possible alternative measures in young, even-aged forest stands, as well as possible ways of estimating consequences (IP 1). In other words, the aims of the process were open and general; it was up to the stakeholders to decide how to define the most important aspects (IP 1). Although it was important that the discussions stayed within the current governance framework of Swedish forest use because the results would feed into current policy and practice, in reality, Swedish forest owners have considerable room to maneuver in managing their forests. The stakeholder discussions focused solely on aspects of management in the young phase, leaving out other aspects of the rotation period such as regeneration methods after final cut and commercial thinning. It was also made clear from the beginning that consensus among the stakeholders was neither possible nor desirable.

An important point of departure was that the results of the process should be useful to forest owners in their production forests. This meant that suggestions had to be in line with the current Forest Act and general forest policy, and the Forest Agency had to be able to stand behind the final content. According to present forest policy, it is very important for the future development of a forest stand to take measures before the trees reach the size at which they can provide commercial stem wood. Therefore, precommercial thinning is recommended to improve the overall economy of a full rotation cycle, determine tree species
Table 3. Objectives of the collaborative process.

\begin{tabular}{ll}
\hline \hline Number & Objective \\
\hline 1 & $\begin{array}{l}\text { Test the methodology of structured decision making (SDM) on } \\
\text { a national forest related case; testing the SDM model in this } \\
\text { context is as important as developing the decision support } \\
\text { options }\end{array}$ \\
& $\begin{array}{l}\text { Develop decision support for case-adapted young forest } \\
\text { management based on what different stakeholders think young } \\
\text { forest management should accomplish. The decision support } \\
\text { should allow for increased production and greater variety in } \\
\text { forest management based on the perspective that forest owners } \\
\text { may have, i.e., what they consider important to achieve. The data } \\
\text { will then be further developed by the Forest Agency into a useful } \\
\text { decision support system }\end{array}$ \\
\hline
\end{tabular}

composition, avoid mortality and self-thinning, promote the growth of remaining trees, and favor quality development of the stand. The Forest Agency has been concerned about the low use of precommercial thinning after the deregulation of the Forest Act in the 1990s. Another specific goal of current Swedish forest policy is to increase variety in the management of Swedish forests (Swedish Forest Agency 2016b). Thus, another important objective was to develop management alternatives that could contribute to more varied forestry and increase interest among landowners in managing the forest in the young forest phase, assuming a silvicultural system based on even-aged management (IP 2). Given these broad objectives, it was necessary to have a wide range of stakeholder viewpoints. 
From this point on, the main objective of the process was linked to the development of various options that forest owners could use to meet their objectives in forest management (Table 4). To capture the different needs and objectives of forest owners, the discussions started with the question, "What is important in young forest management, in the shorter and longer term?" All stakeholders were given an opportunity to clarify their perspectives and priorities in open discussion. From the start, it was clear that many of the identified objectives could be merged. For instance, forest damage was seen as a bigger problem when moose (Alces alces) and other ungulate species such as roe deer (Capreolus capreolus), fallow deer (Dama dama), and red deer (Cervus elaphus) are present. This was not the case for semidomesticated reindeer (Rangifer tarandus tarandus) because they do not feed on trees, even though damage sometimes occurs from, for example, trampling.

Table 4. Examples of fundamental objectives.

\begin{tabular}{ll}
\hline \hline Stakeholder & Objective \\
\hline Reindeer & A future for reindeer husbandry \\
herders & $\begin{array}{l}\text { Sustainable use; we are borrowing from nature } \\
\text { Reindeer's well-being }\end{array}$ \\
Forest & Optimal financial return in the short and long term \\
companies & Forestry that is widely accepted in society \\
Hunters & More game \\
& Less damage \\
& Beautiful landscape \\
\hline
\end{tabular}

\section{Developing alternatives and evaluating consequences and trade- offs}

After the decision context had been clarified, the stakeholders formulated possible management objectives (Table 5). This step was necessary because the Agency formulated the task quite broadly, and the exercise was meant to provide support for further discussion and move the work forward. As background to the exercise, some of the stakeholders were given an opportunity to present their thoughts on the changes they would like to see in the present management of young, even-aged forests. The results of this exercise built on the previous discussions of what the stakeholders thought were important consequences of management in the young phase.

In the subsequent step, the stakeholders discussed ways to develop measures and criteria for later evaluation of management options. Both of these issues prompted much discussion among the stakeholders. Some of them argued that current forest management should form the basis for the options, whereas others argued that a focus on traditional even-aged forestry would lead to too little innovation and the risk of developing a silo mentality. The discussions revealed that it was difficult to develop measures and criteria for evaluation that everyone in the group could agree on, and so this step in the process was postponed.

Unresolved issues following the first two meetings with the stakeholders required some additional work between these meetings before the group decided to move forward. However, the first step of SDM (clarifying objectives) was not closed. The stakeholders identified a number of management objectives so that they could continue working on the next step to develop measures or criteria that could be used to show how the different management alternatives live up to what stakeholders think are important considerations in the young phase.

Table 5. Decision options.

\begin{tabular}{|c|c|}
\hline Number & Option \\
\hline 1. A1 & $\begin{array}{l}\text { Varied forests, rich in biodiversity; multilayered heterogeneous } \\
\text { stand structure; management based on natural disturbance } \\
\text { regimes }\end{array}$ \\
\hline 2. A2 & $\begin{array}{l}\text { Varied forests, rich in biodiversity; even-aged stands dominated } \\
\text { by broadleaf trees }\end{array}$ \\
\hline 3. B & Appreciation for recreational and outdoor activities \\
\hline 4. $\mathrm{C}$ & $\begin{array}{l}\text { High biomass production of lichens; open stand structures; easy } \\
\text { to access for reindeer and people }\end{array}$ \\
\hline 5. D & $\begin{array}{l}\text { Economically viable forestry; large climate benefit (high net } \\
\text { growth); general concern for other environmental values }\end{array}$ \\
\hline 6. E & $\begin{array}{l}\text { High net growth (dry matter production); profitable production } \\
\text { of biomass for energy }\end{array}$ \\
\hline 7. $\mathrm{F}$ & $\begin{array}{l}\text { High adaptive capacity in relation to climate change and } \\
\text { changed market conditions }\end{array}$ \\
\hline 8. G & $\begin{array}{l}\text { Forests rich in game; minimum game damage to commercial tree } \\
\text { species }\end{array}$ \\
\hline
\end{tabular}

The stakeholders then summarized the differences and similarities they could see in their respective management options. The facilitator asked the stakeholders to reflect on the similarities and differences compared to the nine objectives originally identified by forest owners, as well as on how the results of this exercise could become useful to the Forest Agency. One of the objectives, "varied forest stands with high biodiversity," was then divided into two silvicultural programs: one for multilayered, unevenaged stands and one for broadleaf-dominated, even-aged stands. Two management options, namely "a forest easy to access" and "a forest suitable for reindeer herding," were considered to require the same type of forest management and were thus merged into one. Thereafter, the workgroup entered the final SDM step of formulating silvicultural programs for the agreed-upon eight management objectives (Table 5), which should result in guidance to the Forest Agency's management experts and forest land owners. As part of the dialogue process, specialists from the Agency were then involved. They supported the stakeholders with expertise as they refined and developed more specific stand-based silvicultural programs to meet the identified management objectives. Because forest management depends not only on fundamental objectives but also on geographical and natural conditions, the group agreed to define initial states of the young forest stands. For practical reasons, the stakeholders decided to define four "typical" young forest stands in northern and southern Sweden, for a total of eight typical stands. These stand types became the point of departure for the silvicultural programs developed by the experts.

The next step of the process was to analyze the consequences of the different silvicultural programs. Therefore, the Agency consulted an expert at the Forestry Research Institute of Sweden (Skogforsk). Contact was also established with three forestry experts from the Forest Agency and the advisory and counseling services of the Agency regarding the future handling of the decision options resulting from the collaborative process. At this point, the discussion about criteria and indicators needed to be resumed. This discussion was done at the sixth meeting with the 
stakeholder group, after which the secretariat summarized suggestions for criteria and indicators based on the discussions during this meeting. These suggestions were sent out to all group members for comment and to the expert from Skogforsk. The expert from Skogforsk also presented possibilities and limitations using the Heureka modeling tool (https://www.slu.se/en/ departments/forest-resource-management/program--project/forestsustainability-analysis/heureka/heureka-systemet/en-heureka/). The Heureka forestry decision-support system is a suite of freely available software developed and hosted by the Swedish University of Agricultural Sciences. The system covers the whole decision-support process from data inventory to selection among plan alternatives with multicriteria decision-making techniques. It is used in practical forestry in Sweden today. After suggestions for adjustments, a set of refined criteria was sent to the group. The expert from Skogforsk analyzed the eight silvicultural programs for the eight typical forest stands described earlier. The results were amalgamated and summarized in tables provided to the group members.

The analyses of consequences showed that silvicultural measures and the design of silvicultural programs applied during the young forest phase can have a large effect on what management objectives can be met, both in young managed forests and later during the rotation cycle. It was also obvious that some management objectives could be met by similar silvicultural programs because some programs could meet several objectives. However, other objectives required more specific programs, and balancing against other objectives could not be achieved.

\section{Implementation and way forward}

One strength of the SDM model is that it has a structured approach and permits iteration. The working group can, if necessary, go back to the earlier stages and try new approaches or make additions. The stakeholder group made good use of this opportunity. On several occasions, they made minor corrections in the options and evaluation criteria. Late in the process, they also changed a number of the options to increase differentiation. A final exercise simulated the use of the result to advise forest owners on forest management. After this exercise, the stakeholder group agreed that the mission given by the Forest Agency was now complete and instructed the secretariat to compile a final report (Swedish Forest Agency 2016b).

The result of the collaborative process has now been delivered in the form of a number of suggested silvicultural programs to meet eight different management objectives (summarized in Table 5). This was done for the typical stands in the north and south of Sweden used as a starting point for management in the young phase of even-aged, managed forests. The programs can be seen as examples of objectives that a forest owner could adopt. This outcome was consistent with the decision context because the Forest Agency envisioned decision options that were well described and analyzed in line with current forest policy. Moving forward, the options should provide landowners with recommendations on how to manage the forest in the young phase to stimulate more variation than is currently provided.

Learning from structured decision making: stakeholders' perceptions of the collaborative process

In terms of the decision context, a majority of stakeholders considered the collaborative process to be rather unclear in the beginning (IP 3, 6, 7, 8, 10, 11, 12). Given the complex nature of the task, it was not clear which objectives should be addressed and where they would lead. Some of the stakeholders saw this as an advantage (IP 6, 7, 9, 13), whereas others argued that the mandate and objectives should have been clearer from the outset (IP 3, 8, 10). At the same time, many of the stakeholders reasoned that this was probably a necessary step, although it took some meetings to clarify this before they perceived the process as structured (IP 2, 8, 9). All of the stakeholders considered it reasonable that the group stayed within the framework of current forest policy; otherwise, it would not be useful for forest owners, who were the targeted end-users.

The delimitation of the context was identified as a problem. Because the stakeholders were instructed to discuss management only in the young forest phase, in this case, mainly precommercial thinning, other important silvicultural measures during the rotation period of an even-aged forest stand were left out of the discussion. Although many of the stakeholders argued that this was a reasonable delimitation, they also considered it important to clarify the timescale of forest management, that is, how forest owners undertake silvicultural measures today and how this relates to the forests' future development (IP 3, 8). Thus, the stakeholders often had to remind themselves about this delimitation and stick to the task.

A majority of the stakeholders identified the fact that all of the stakeholders did not participate in all of the meetings as a problem. Nonattendance was due to other priorities, often related to their day-to-day work, lack of time, and in some cases, lack of financial resources. Some of the stakeholders argued that it would have been helpful if the meetings could have been held over several consecutive days rather than being spread out over time (IP 5, 7, $9,11,13)$. The length of time between meetings made it easy to forget what had been discussed at the previous meeting. Furthermore, stakeholders stressed that they had not actually gained more knowledge about young stand management after the process, indicating that they considered the learning process on SDM more rewarding (IP 3, 8, 10, 11).

There was, however, no real discussion about how to make tradeoffs between different management objectives. Stakeholders pointed out that there may be several different ways to meet a particular objective. They indicated that there is a need to demonstrate the effects of a management system that accommodates multiple values, for example, benefiting both game and timber production. However, it is difficult to quantify the effects of factors such as browsing damage and loss of biodiversity (IP 2, 3, 7). Stakeholders drew attention to the fact that it would be beneficial if problems related to forest damage, such as those caused by game, could be handled at the landscape level. Failure to do so was considered a shortcoming of current management (IP 2, 7, 9).

In terms of the results of the process, the final silvicultural programs developed by the Agency's experts were generally reasonable, and no major concerns were identified. Some of the stakeholders noted that the objectives were still developed within the framework of traditional even-aged forestry and that the silvicultural programs were standard solutions with few surprises (IP 7, 11, 12, 13). Some stakeholders also complained that they were given little insight into how the silvicultural programs were 
designed in detail (IP 7, 11, 13). Moreover, a majority of the stakeholders argued that the eight final decision options were not particularly visionary, making it possible to scrutinize the content and provide even fewer, more comprehensive instructions for future management (IP 3, 6, 7).

In general, the stakeholders were positive toward the collaborative process and the SDM approach, but when asked to describe the model in their own words, almost none of them could easily do so. A clear majority felt that the discussions had been respectful and transparent and that the facilitator had done a very good job of keeping the group together and providing valuable information and feedback. Most importantly, all of the stakeholders' views and opinions were respected, which is reflected in the eight options that came out of the process. This would certainly not have been the case if a smaller number of proposals had been discussed. In general, the proliferation of interest groups was considered good, and many different perspectives were brought to the table, although some stakeholders raised the importance of keeping the discussions open (IP 6, 9, 11). It is important to stress that all of the stakeholders who did not have a forest owner perspective argued that it was important to look beyond the financial perspectives of forestry, although a financial perspective was often the focus of the discussions. One issue that was raised in the interviews was "What actually is an economic profit, and for whom?" (IP 11, 13). From a forest owner perspective, however, the tendency was to think in the opposite direction. One respondent stated, "We already work with different values every day in our management operations," (IP 3), and a common viewpoint was expressed in the following way: "You cannot maximize all values in the same stand; you simply have to pick and choose," (IP 3).

At the end of the process, a majority of the stakeholders were still uncertain about how the Forest Agency would proceed with the decision options. However, everyone agreed that it was important that private landowners receive updated recommendations, especially because many options are actually within the framework of current laws and regulations. Thus, some of the stakeholders were a bit pessimistic about the potential of the collaborative process (IP 3, 8, 11, 13). They felt that it was unlikely that large-scale forest companies would benefit from the results. From a forest owners' perspective, the options identified were seen as fairly obvious. Thus, it was considered important to recognize that a forest owner may have different objectives with his or her forestry (IP 4, 5, 7, 11, 12, 13).

\section{DISCUSSION AND CONCLUSIONS}

Here, our aim was to analyze the feasibility and practical relevance of collaboration and dialogue inspired by SDM in the governance of multiple forest values. Our empirical case study drew on a collaborative process to improve the management of young, evenaged forest stands in Sweden. For a number of reasons, the Forest Agency deviated from the original SDM approach. For instance, we identified the absence of a formal decision maker and a lack of alternative strategies and their estimated consequences. The decision context was not clarified from the beginning; rather, developing a context was viewed as a part of the collaborative process. However, the process would have gained value had the context been determined previously. Because the process was guided by the formulation of many different decision options, key trade-offs were largely left to individual landowners in the form of a "pick-and-choose" support option. It was also clear that little attention was given to the identification of possible knowledge gaps relevant to the quality of the decision making. In the absence of an identified decision maker, the aim of the process turned into the development of new decision options for the Forest Agency's counseling services and updating advice to forest owners in their management planning. As such, the results fit very well into the underlying principle of "freedom with responsibility" of Swedish forest policy and the overarching idea of achieving more variation in Swedish forestry. However, the lack of discussions on tradeoffs between different management objectives may well result in ambiguity. Furthermore, there are several ways to meet a particular objective, and the discussions would have gained value if this idea had been clarified. There is a risk that a collaborative process will retain the same level of uncertainty as before the process and that the initial visions return to the status quo. However, given the "more-of-everything" pathway and the ambitions of adaptive management in Swedish forest policy, key trade-offs are particularly important to bring to the table. It should also be acknowledged that different stakeholders have different perspectives and priorities, which affect how "freedom with responsibility" is interpreted in practice. Even so, because Swedish forest policy relies extensively on collaboration to reach tangible and sustainable outcomes, it is vital to find new ways of harmonizing multiple values (Mårald et al. 2015, Johansson 2016).

Given the context, it was probably necessary to make many adaptations of the SDM process to fit the Swedish system. However, as a result, this study can only shed light on the ways in which an SDM approach can be interpreted and developed in this context and cannot provide answers about its full applicability. Regarding generalizability, we do not claim to have generated results that are directly applicable to any case of SDM in the forest sector in Sweden or elsewhere (see Ogden and Innes 2009, Marcot et al. 2012, Ferguson et al. 2015). Despite the limitations of this study, it confirms and sheds additional light on the struggles that resource agencies deal with when setting up collaborative processes. For instance, it was difficult for the Forest Agency to get broad participation and to engage all stakeholders to commit and dedicate time to the process. For some of the stakeholders, collaborative processes are not considered part of their daily work, and when they had to prioritize their tasks, the meetings were not their first priority. At the end of the process, some issues still remained unclear, including how the silvicultural programs would be made practically useful and accessible to forest owners. Furthermore, concerns were raised about the lack of novelty of the options. As a result, it was uncertain to what extent the options would contribute to a more varied forest landscape that takes multiple values into consideration.

On a positive note, the results show that the SDM rationale of step-by-step teamwork, the involvement of expertise, and guidance by an independent facilitator fostered trust among the stakeholders and between them and the Agency. A number of positive results were identified by a majority of the stakeholders, including the creation of genuine discussion with consideration of different interests and values. Such social learning, or "soft" fallouts, should not be dismissed when it comes to the implementation of forest management in countries that rely on 
voluntary participation to reach often competing objectives. Our study confirms the importance of devoting careful attention to the process of stakeholder dialogue and not merely its results. Despite the fact that a majority of the stakeholders were highly unsure about how the decision options would be made practically relevant and accessible to landowners and whether they would actually produce any changes on the ground, they were generally positive toward the SDM approach. In particular, this attitude was the result of stepwise work under the guidance of an independent and skilled facilitator. In general, stakeholders recognized value differences and were able to revise their own positions. However, it must be acknowledged that the management of forests in the young phase, as it is undertaken today, is not one of the most controversial issues in Swedish forestry, even though it is complex (Mårald et al. 2015). This point is confirmed by examining the final decision options. Consistent with Ferguson et al. (2015), we found no drastically different objectives among the stakeholders, and many of the decision options could be merged. We also could not identify a single best management option. Rather, the main objective of the process was to inform forest owners about a variety of decision options suitable for all of the goals a forest owner might have. Another objective was to make forest owners aware of potential trade-offs between different goals. Despite the fact that the stakeholders represented different interests, we argue that the outcomes of the process were determined by the open decision atmosphere and by the various objectives available from the start.

This case study has enabled us to identify many advantages of a collaborative process inspired by a structured decision approach when the issue at hand is multifaceted and complex. It is important to stress that collaborative processes in forest management need to consider adaptability at all stages. In our case, an adaptive model functioned relatively well despite, or perhaps because of, deviations from the initial model early in the process. Because many steps in the process worked, it can be argued that there is empirical support for SDM, although the model needs to be adapted to real settings. We recommend that resource agencies continue to use this model and develop processes suitable for each particular context. This development will include a careful choice of issues to be handled and how the issues are linked to policy or decision-making processes. It also involves a well-designed process in which the roles and responsibilities of the actors involved, both the public agency and the stakeholders, are recognized. Finally, it also requires access to appropriate expertise and decision-support tools to facilitate the comparison of relevant decision alternatives.

Responses to this article can be read online at: http://www.ecologyandsociety.org/issues/responses. $\mathrm{php} / 10347$

\section{Acknowledgments:}

This study was written as part of the Future Forests interdisciplinary research program financed by MISTRA (the Foundation for Strategic Environmental Research), the Forestry Research Institute of Sweden, the Swedish University of Agricultural Sciences, and
Umeå University. We thank the anonymous reviewer and the subject editor for valuable comments. We also thank Professor Emeritus Stig Larsson for valuable discussions on structured decision making.

\section{LITERATURE CITED}

Ansell, C., and A. Gash. 2007. Collaborative governance in theory and practice. Journal of Public Administration Research and Theory 18(4):543-571. http://dx.doi.org/10.1093/jopart/mum032

Beland Lindahl, K., A. Sténs, C. Sandström, J. Johansson, R. Lidskog, T. Ranius, and J.-M. Roberge. 2017. The Swedish forestry model: More of everything? Forest Policy and Economics 77:44-55. https://doi.org/10.1016/j.forpol.2015.10.012

Bjärstig, T., and A. Sténs. 2018. Social values of forests and production of new goods and services: the views of Swedish family forest owners. Small-scale Forestry 17(1):125-146. http:// dx.doi.org/10.1007/s11842-017-9379-9

Bodin, Ö. 2017. Collaborative environmental governance: achieving collective action in social-ecological systems. Science 357:eaan1114. http://dx.doi.org/10.1126/science.aan1114

Denhardt, J. V., and R. B. Denhardt. 2011. The new public service: serving, not steering. Third edition. M.E. Sharpe, Armonk, New York, USA.

Emerson, K., and T. Nabatchi. 2015. Evaluating the productivity of collaborative governance regimes: a performance matrix. Public Performance and Management Review 38(4):717-747. http://dx.doi.org/10.1080/15309576.2015.1031016

Ewen, J. G., L. Walker, S. Canessa, and J. J. Groombridge. 2015. Improving supplementary feeding in species conservation. Conservation Biology 29(2):341-349. http://dx.doi.org/10.1111/ cobi. 12410

Ferguson, P. F. B., M. J. Conroy, J. F. Chamblee, and J. HepinstallCymerman. 2015. Using structured decision making with landowners to address private forest management and parcelization: balancing multiple objectives and incorporating uncertainty. Ecology and Society 20(4):27. http://dx.doi. org/10.5751/ES-07996-200427

Gregory, R., L. Failing, M. Harstone, G. Long, T. McDaniels, and D. Ohlson. 2012. Structured decision making: a practical guide to environmental management choices. Wiley-Blackwell, Chichester, UK. http://dx.doi.org/10.1002/9781444398557

Gregory, R., T. McDaniels, and D. Fields. 2001. Decision aiding, not dispute resolution: creating insights through structured environmental decisions. Journal of Policy Analysis and Management 20(3):415-432. http://dx.doi.org/10.1002/pam.1001

Howlett, M., and J. Rayner. 2006. Globalization and governance capacity: explaining divergence in national forest programs as instances of "next-generation" regulation in Canada and Europe. Governance 19(2):251-275. http://dx.doi.org/10.1111/ j.1468-0491.2006.00314.x

Hysing, E. 2009. From government to governance? A comparison of environmental governing in Swedish forestry and transport. Governance 22(4):647-672. http://dx.doi.org/10.1111/ j.1468-0491.2009.01457.x 
Irwin, B. J., M. J. Wilberg, M. L. Jones, and J. R. Bence. 2011. Applying structured decision making to recreational fisheries management. Fisheries 36(3):113-122. http://dx.doi. org/10.1080/03632415.2011.10389083

Johansson, J. 2013. Constructing and contesting the legitimacy of private forest governance: the case of forest certification in Sweden. Dissertation. Umeå University, Umeå, Sweden. [online] URL: http://umu.diva-portal.org/smash/record.jsf?pid=diva $2 \%$ $\underline{3 \mathrm{~A} 585033 \& \mathrm{dswid}=2885}$

Johansson, J. 2016. Participation and deliberation in Swedish forest governance: the process of initiating a National Forest Program. Forest Policy and Economics 70:137-146. http://dx.doi. org/10.1016/j.forpol.2016.06.001

Johansson, J., and E. C. H. Keskitalo. 2014. Coordinating and implementing multiple systems for forest management: implications of the regulatory framework for sustainable forestry in Sweden. Journal of Natural Resources Policy Research 6 (2-3):117-133. http://dx.doi.org/10.1080/19390459.2014.913363

Kangas, A., N. Saarinen, H. Saarikoski, L. A. Leskinen, T. Hujala, and J. Tikkanen. 2010. Stakeholder perspectives about proper participation for Regional Forest Programmes in Finland. Forest Policy and Economics 12(3):213-222. http://dx.doi. org/10.1016/j.forpol.2009.10.006

Kozak, J. P., and B. P. Piazza. 2015. A proposed process for applying a structured decision-making framework to restoration planning in the Atchafalaya River basin, Louisiana, U.S.A. Restoration Ecology 23(1):46-52. http://dx.doi.org/10.1111/ rec. 12125

Lockwood, M., J. Davidson, A. Curtis, E. Stratford, and R. Griffith. 2010. Governance principles for natural resource management. Society and Natural Resources 23(10):986-1001. http://dx.doi.org/10.1080/08941920802178214

Mårald, E., C. Sandström, L. Rist, O. Rosvall, L. Samuelsson, and A. Idenfors. 2015. Exploring the use of a dialogue process to tackle a complex and controversial issue in forest management. Scandinavian Journal of Forest Research 30(8):749-756. http://dx. doi.org/10.1080/02827581.2015.1065343

Marcot, B. G., M. P. Thompson, M. C. Runge, F. R. Thompson, S. McNulty, D. Cleaves, M. Tomosy, L. A. Fisher, and A. Bliss. 2012. Recent advances in applying decision science to managing national forests. Forest Ecology and Management 285:123-132. http://dx.doi.org/10.1016/j.foreco.2012.08.024

Neckles, H. A., J. E. Lyons, G. R. Guntenspergen, W. G. Shriver, and S. C. Adamowicz. 2015. Use of structured decision making to identify monitoring variables and management priorities for salt marsh ecosystems. Estuaries and Coasts 38(4):1215-1232. http://dx.doi.org/10.1007/s12237-014-9822-5

Ogden, A. E., and J. L. Innes. 2009. Application of structured decision making to an assessment of climate change vulnerabilities and adaptation options for sustainable forest management. Ecology and Society 14(1):11. http://dx.doi. org/10.5751/ES-02771-140111

Reed, M. S. 2008. Stakeholder participation for environmental management: a literature review. Biological Conservation 141 (10):2417-2431. http://dx.doi.org/10.1016/j.biocon.2008.07.014
Rist, L., A. Felton, E. Mårald, L. Samuelsson, T. Lundmark, and O. Rosvall. 2016. Avoiding the pitfalls of adaptive management implementation in Swedish silviculture. Ambio 45(S2):140-151. http://dx.doi.org/10.1007/s13280-015-0750-9

Royal Swedish Academy of Agriculture and Forestry. 2015. Forests and forestry in Sweden. Royal Swedish Academy of Agriculture and Forestry (KSLA), Stockholm, Sweden. [online] URL: https://www.skogsstyrelsen.se/globalassets/in-english/forestsand-forestry-in-sweden 2015.pdf

Sarkki, S., and H. I. Heikkinen. 2015. Why do environmentalists not consider compromises as legitimate?: Combining value- and process-based explanations from Finnish forest controversies. Forest Policy and Economics 50:110-117. https://doi.org/10.1016/ j.forpol.2014.08.004

Schlyter, P., and I. Stjernquist. 2010. Regulatory challenges and forest governance in Sweden. Pages 180-196 in K. Bäckstrand, J. Kahn, A. Kronsell, and E. Lövbrand, editors. Environmental politics and deliberative democracy: examining the promise of new modes of governance. Edward Elgar, Cheltenham, UK. http://dx. doi.org/10.4337/9781849806411.00020

Sundström, G. 2010. In search of democracy. The process behind the Swedish forest-sector objectives. Pages 79-93 in G. Sundström, L. Soneryd, and S. Furusten, editors. Organizing democracy: the construction of agency in practice. Edward Elgar, Cheltenham, UK.

Swedish Forest Agency. 2013. Adaptiv skogsskötsel. Meddelande 3. Skogsstyrelsen, Jönköping, Sweden. [online] URL: https:// shopcdn.textalk.se/shop/9098/art72/17826572-f607c8-1586.pdf

Swedish Forest Agency. 2016a. Adaptiv skogsskötsel 2013-2015. Meddelande 7. Skogsstyrelsen, Jönköping, Sweden. [online] URL: https://shopcdn.textalk.se/shop/9098/art7/69700407-6ce43fAdaptiv skogsskotsel webb.pdf

Swedish Forest Agency. 2016b. Målanpassad ungskogsskötsel. Rapport 13. Skogsstyrelsen, Jönköping, Sweden. [online] URL: https://shopcdn.textalk.se/shop/9098/art8/110056808-1b4ea4Malanpassad skogsskotsel webb.pdf

Uggla, Y., M. Forsberg, and S. Larsson. 2016. Dissimilar framings of forest biodiversity preservation: uncertainty and legal ambiguity as contributing factors. Forest Policy and Economics 62:36-42. http://dx.doi.org/10.1016/j.forpol.2015.07.007

Wellstead, A. M., M. Howlett, and J. Rayner. 2013. The neglect of governance in forest sector vulnerability assessments: structural-functionalism and "black box" problems in climate change adaptation planning. Ecology and Society 18(3):23. http:// dx.doi.org/10.5751/ES-05685-180323

Wesserlink, A., J. Paavola, O. Fritsch, and O. Renn. 2011. Rationales for public participation in environmental policy and governance: practitioners' perspectives. Environment and Planning A 43(11):2688-2704. https://doi.org/10.1068/a44161

Westberg, L., and C. Waldenström. 2017. How can we ever create participation when we are the ones who decide? On natural resource management practice and its readiness for change. Journal of Environmental Policy and Planning 19(6):654-667. http://dx.doi.org/10.1080/1523908X.2016.1264298 